\title{
Una risposta che non pecca in chiarezza
}

\section{Giuseppe Patota}

PUBBLICATO: 10 NOVEMBER 2020

\section{Quesito:}

Diversi utenti denunciano incertezze nell'uso del verbo peccare, anche in relazione al significato che di volta in volta può assumere: i più chiedono come debba intendersi l'espressione peccare di qualcosa, mentre uno di loro domanda se sia possibile usare peccarmi.

\section{Una risposta che non pecca in chiarezza}

Tubbi di chi ci ha scritto sono pienamente comprensibili e perfino condivisibili.

Proviamo a mettere un po' d'ordine.

Il verbo peccare può avere tre significati diversi ed essere al centro di tre diversi tipi di enunciati, i quali mettono in scena, per cosi dire, tre diversi tipi di situazione.

Un primo significato del verbo peccare è quello di 'commettere un peccato', 'commettere un'infrazione morale'. In questo caso, il verbo può essere completato dal solo soggetto, come nell'esempio (I), oppure può essere completato dal soggetto e da un nome (indicante l'àmbito relativo al peccato, che è sempre qualcosa di negativo) preceduto dalla preposizione di, come nell'esempio (2). Quando peccare ha questo significato pertinente alla religione e alla morale, il luogo figurato in cui si pecca è indicato da un nome preceduto dalla preposizione in, come nell'esempio (3):

(I) Padre, perdonatemi perché (io) ho peccato.

(2) Gli uomini peccano spesso d'invidia, di gola, avarizia, ecc.

(3) Ho peccato in pensieri, in parole, in opere e in omissioni.

Un secondo significato del verbo peccare è quello di 'commettere un errore'. In questo caso, il verbo è completato, oltre che dal soggetto, da un nome indicante l'ambito in cui si commette l'errore (e anche in questo caso si tratta di un àmbito negativo) preceduto dalla preposizione di, come negli esempi (4) e (5):

(4) Il tuo ragionamento pecca d'imprecisione.

(5) Il loro comportamento pecca di slealtá.

Un terzo significato del verbo peccare è quello di 'mancare', 'avere difetto'. In questo caso, il verbo è completato, oltre che dal soggetto (sempre rappresentato da un oggetto, mai da una persona), da un nome indicante l'àmbito relativo a ciò che manca (che in questo caso è sempre positivo) preceduto dalla preposizione in, come negli esempi (6) e (7):

(6) Il tuo ragionamento pecca in precisione.

(7) Il vostro comportamento pecca in correttezza. 
Su questa base, rispondiamo ai singoli quesiti. "Il verbo peccare - scrive Martina - mi confonde: peccare d'invidia vuol dire 'essere invidiosi'? Peccare di carisma vuol dire averne poco?". La risposta è sì nel primo caso e no nel secondo, che richiede un'altra preposizione: Peccare in carisma. Federica incalza: peccare di sincerità significa 'essere poco sinceri', come sostengono i suoi amici, o designa una schiettezza estrema, come ritiene lei? Poiché la sincerità non è da considerare un difetto, peccare di sincerità sembra poco ammissibile nel senso di 'essere di una schiettezza estrema', mentre per sostenere che una persona è poco sincera bisognerebbe dire peccare in sincerità. La stessa risposta vale per Maurizio a proposito di peccare di modestia. Infine, essendo peccare intransitivo, l'uso riflessivo indicato da Marco è inammissibile.

\section{Cita come:}

Giuseppe Patota, Una risposta che non pecca in chiarezza , "Italiano digitale", 2020, XV, 2020/4 (ottobre-dicembre)

DOI: 10.35948/2532-9006/2020.4419

\section{Copyright 2020 Accademia della Crusca}

Pubblicato con licenza creative commons CC BY-NC-ND 